\title{
Thyolrographic Sheet.
}

\section{$\checkmark$}

Shecicuevo repistered Tamang 5.1885

\section{Sea Bottom Specimens.}

1884.II. N.T.and Del. - DelawareBay Entrance.

Tulary. No.l.

. 2

. 3.

. $4 \%$

.5.

.6 .

.$\%$

, 9.

$-10$.

/1.

"1R.

.3.

$-14$.

15.

16.

$.1 \%$

.18.

"19.

" 20.

"R/.

22.

. 23.

.24.

$-25$.

$-26$.

$2 \%$
8-2. g.s.andz.

4 -0is. fmevos.

briz. Sr.

$4-2 \%$ fuc. $9 y .5$.

$4-3.2$ ?

6-5. bre. Sh.anes?

H-2. exs.gy.8. rorte. Sh.

Fis. 2 :

8-0. en.g. S. Thite. St.

Y-0. b\%.0.

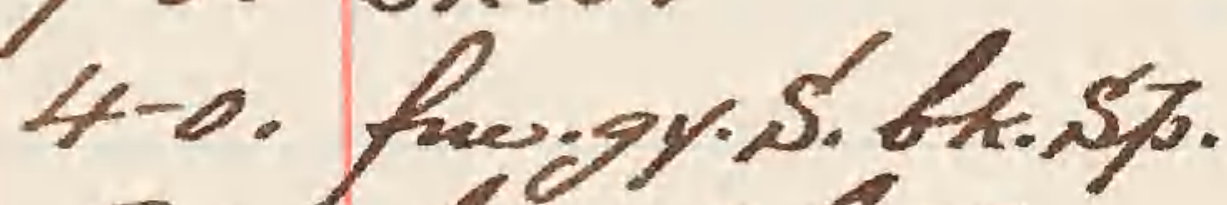

5-o. bit. vare.?

s-a. fae.dagy s.

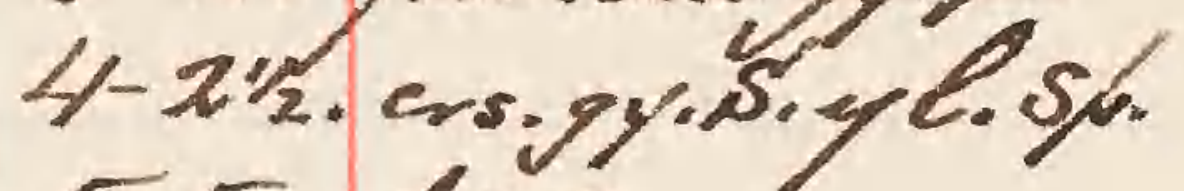

5.5. Kh. O.

4-3. biz. Sh.

6-3. cos.gy.s.

7-2. faregy.s.

5-41/2. ens.gy.S.T.TSts.

$5=0$. P.tha.showith int cos.gy.s. $5-112$. ens.gy. $S$.

13-0. bh.l. 6-4. ens.g. S.p.rimt. sh.

6-3. en.2. Sh.

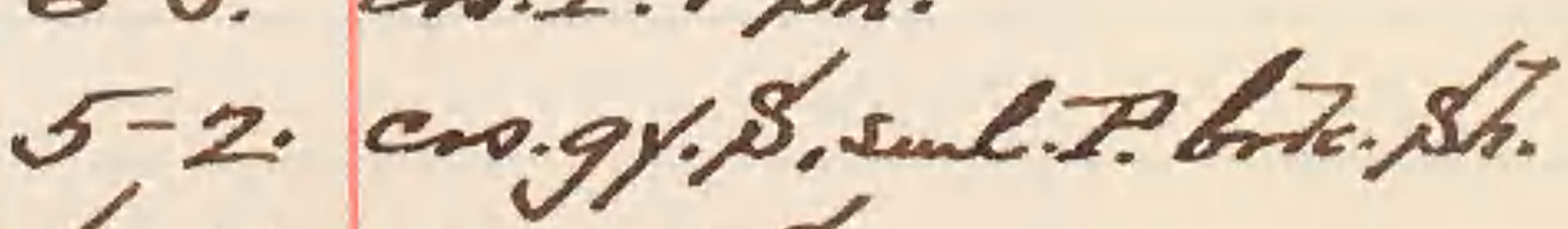

6-2. enoy.s.

$7-4 . \ln 2$. 


\section{Satej feation
7884 No.}

c

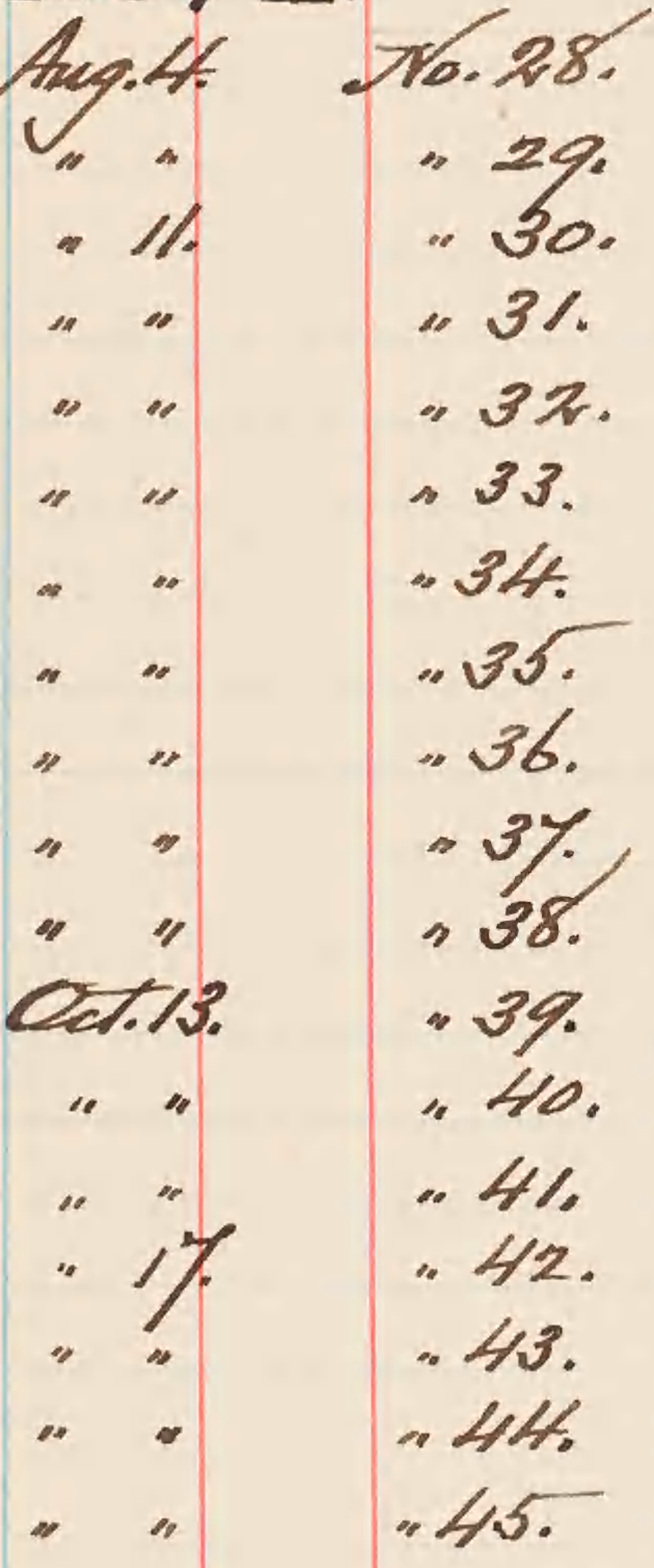

tyates.

Ab, Teanauce.

4-3. hu. g. S. HK. S\%.r.t.

6-21. ens.gy.S.R. notk. Sh.

5-3. exsy. 5.5 remat.

6-0\%.crs. gy.S.P. LR. Sh.

5.3. ens.gy. S. frew his. Sh.

SF112:9y.S.

5-3\%. ers.s. Lis. Sh.

to. fas ment.R.

6-5. ers.S.P. .brk. Sh.

4-2. P.nSt.

q-3. ess.gy.s. Lh.sh.br.s\%.se.

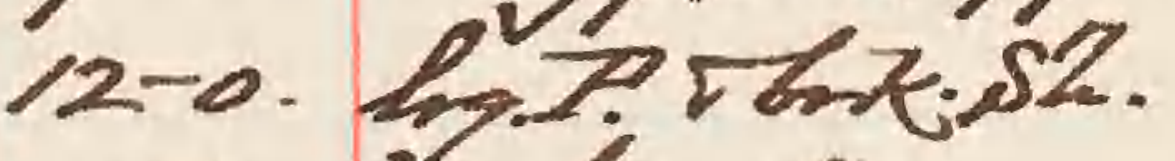

15-0. 2. L7. 57.

14-5. O.gy-bi. S. Whit.Sh.

$1 Y$ D. ens.Zus. faw. E.

1.to. ha. sy.s.bk. S\%.

itt-o. fac gV S. AR. St.

$14-2$. fix. $9 y, \$$. $P$. 